\title{
Perfil epidemiológico em território brasileiro dos acidentes causados por animais peçonhentos: retrato dos últimos 14 anos
}

\author{
Epidemiological profile of accidents caused by venomous animals in Brazil: portrait of the \\ last 14 years
}

Perfil epidemiológico de los accidentes causados por animales venenosos en Brasil: retrato de los últimos 14 años

Maria Eduarda Zen Biz ${ }^{1 *}$, Gabriela Cascardo Cernadela Azeredo², João Frigini Junior ${ }^{3}$, Heloisa Dutra Panhoca ${ }^{4}$, Tauany Maria de Cássia Souza ${ }^{5}$, Mayara Cristine Crovador ${ }^{6}$, Priscila Pereira Cavalheiro ${ }^{7}$, Bruno Cezario Reis ${ }^{8}$.

\section{RESUMO}

Objetivo: Analisar prevalência e identificar perfil dos pacientes acometidos por acidentes por animais peçonhentos no território brasileiro. Métodos: Estudo transversal descritivo através de dados epidemiológicos. Informações foram obtidas no DATASUS, nas subseções do Sistema de Informação de Agravos de Notificação (SINAN) e Sistema de Informações sobre Mortalidade (SIM). Resultados: Foram notificados 2.456.217 acidentes com animais peçonhentos no Brasil. O sexo mais acometido foi masculino (56\%), a faixa etária mais comum é 20 e 39 anos, a raça predominante foi parda $(42,8 \%)$ e escolaridade do $5^{\circ}$ ao $8^{\circ}$ anos incompletos (11,4\%). O agente agressor de destaque foi escorpião $(51,2 \%)$ e na evolução, houve predomínio da cura sem sequelas $(91,5 \%)$. No SIM, a região Nordeste se destacou quanto à quantidade de falecimentos (14,3\%) e 2019 obteve maior soma de mortes $(4,6 \%)$. O maior número de óbitos acometeu a população masculina (33,79\%), acima dos 60 anos (8,7\%), pessoas pardas $(25,8 \%)$ e com 1 a 3 anos estudados (12,3\%). Conclusão: Há alta prevalência de acidentes e correlação com urbanização, ocupação e bioma. Acometidos são jovens do sexo masculino, com baixa escolaridade e cor parda. Mortalidade associa-se a idade, espécies e atendimento.

Palavras-chave: Epidemiologia, Brasil, Animais peçonhentos.

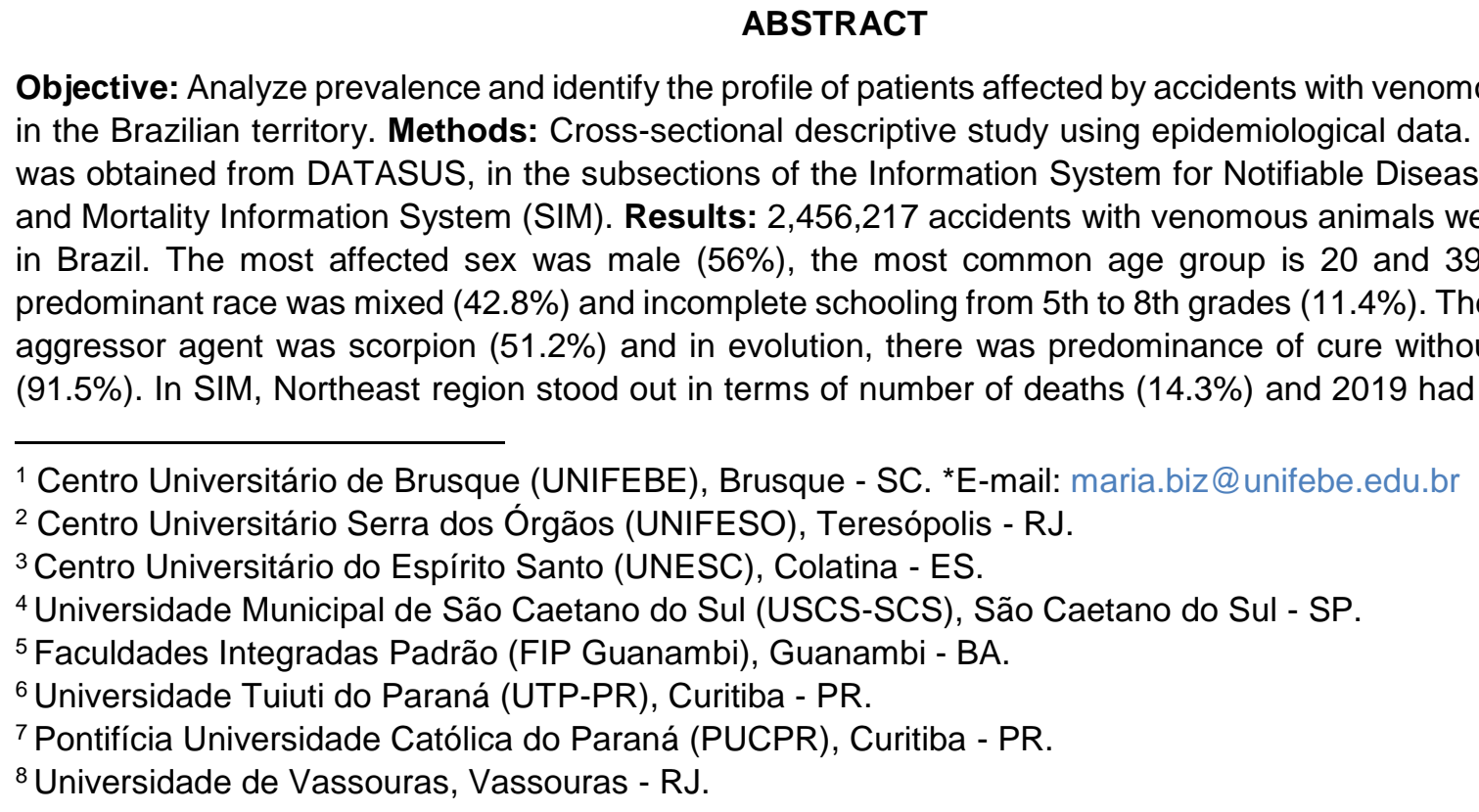

SUBMETIDO EM: 11/2021

ACEITO EM: 11/2021

PUBLICADO EM: 11/2021 
sum of deaths (4.6\%). The greatest number of deaths affected the male population (33.79\%), over 60 years old $(8.7 \%)$, brown people $(25.8 \%)$ and with 1 to 3 years of study $(12.3 \%)$. Conclusion: There is high prevalence of accidents and correlation with urbanization, occupation and biome. Affected are young males, with low education and brown color. Mortality is associated with age, species and care.

Keywords: Epidemiology, Brazil, Venomous animals.

\section{RESUMEN}

Objetivo: Analizar prevalencia e identificar perfil de pacientes afectados por accidentes con animales venenosos en el territorio brasileño. Métodos: Estudio descriptivo transversal utilizando datos epidemiológicos. La información se obtuvo de DATASUS, en subsecciones Sistema de Información de Enfermedades de Notificación (SINAN) y Sistema de Información de Mortalidad (SIM). Resultados: Se reportaron 2.456.217 accidentes con animales venenosos en Brasil. El sexo más afectado fue masculino (56\%), el grupo de edad más común es de 20 y 39 años, la raza predominante fue mestiza $(42,8 \%)$ y la escolaridad incompleta de $5^{\circ}$ a $8^{\circ}$ grado $(11,4 \%)$. El agente agresor destacado fue escorpión $(51,2 \%)$ y la evolución predominó curación sin secuelas $(91,5 \%)$. En SIM, región Nordeste se destacó en términos de número de muertes $(14,3 \%)$ y 2019 tuvo la mayor suma de muertes $(4,6 \%)$. El mayor número de defunciones afectó a la población masculina (33,79\%), mayores de 60 años $(8,7 \%)$, morenos $(25,8 \%)$ y con 1 a 3 años de estudio (12,3\%). Conclusión: Existe alta prevalencia de accidentes y correlación con urbanización, ocupación y bioma. Afectados son machos jóvenes, con baja escolaridad y color marrón. Mortalidad está asociada con edad, especie y cuidados.

Palabras clave: Epidemiología, Brasil, Animales venenosos.

\section{INTRODUÇÃO}

O processo de urbanização e crescimento do Brasil ocorreu de forma desalinhada, propiciando um desequilíbrio ecológico no ambiente tropical. Com isso, animais peçonhentos e humanos começaram a dividir cada vez mais os mesmos espaços, aumentando a frequência de tais animais venenosos com o homem. Dessa forma, surge um problema no sistema de saúde devido ao prejuízo orgânico somado ao risco de complicações dessa interação (BRAGA JRM, et al., 2021).

Há mais de 10 anos, os acidentes por animais peçonhentos foram adicionados à lista de notificação compulsória (LNC) (BRAGA JRM, et al., 2021). E, segundo o Ministério da Saúde, entre 2000 e 2016, houve um crescimento no registro de ocorrências de 440,87\% (TAVARES AV, et al., 2020). Adicionalmente, as picadas por cobra correspondem mundialmente a uma incidência anual de 2,7 milhões de casos (SANCHEZCASTRO EE, et al., 2021), e as de escorpião cerca de 1,5 milhões (FEOLA A, et al., 2020). Por conseguinte, é notório que a frequente documentação destes acidentes é benéfica, visto que, auxilia no desenvolvimento do sistema de monitorização (FERREIRA ICS e BORGES GH, 2020).

Os animais peçonhentos são identificados pela existência de um aparelho inoculador capaz de inserir as toxinas produzidas através de suas glândulas. Assim sendo, as serpentes realizam a inoculação através de uma dentição na parte anterior, as aranhas pelas quelíceras, enquanto os escorpiões através do aguilhão (FERREIRA ICS e BORGES GH, 2020). Vale ressaltar que, os acidentes mais relevantes compreendem os ofídicos (pelos gêneros Bothrops, Micrurus, Crotalus e Lachesis), escorpiônicos (pelo gênero Tityus) e araneísmo (pelos gêneros Phoneutria, Latrodectus e Loxosceles) (CHEUNG R e MACHADO C, 2017).

No que diz respeito ao quadro clínico, os incidentes com cobras frequentemente provocam dor, edema e/ou acúmulo de sangue no local acometido. Ademais, a vítima pode cursar com necrose tecidual e síndrome compartimental. Tais complicações necessitam de uma abordagem cirúrgica e podem causar sequelas anatômicas permanentes. A ferroada causada pelos escorpiões causa dor excessiva e é capaz de acarretar sintomas sistêmicos como êmese, diaforese, oscilações da frequência cardíaca, hipotensão e choque e neurotoxicidade. Outrossim, a picada de aranhas pode evoluir com dor em queimação e úlcera necrótica de variados tamanhos (WARRELL DA, 2019). 
Apesar de o Brasil se tratar de um país que ostenta uma alta incidência de acidentes por animais peçonhentos, tais casos ainda não recebem a atenção que deveriam e, por esta razão, são compreendidos como doenças tropicais negligenciadas (DTN) pela Organização Mundial da Saúde (OMS) (CHEUNG R e MACHADO C, 2017; LADEIRA CGP e MACHADO C, 2017). Amparando-se nesta concepção, entende-se que a análise dos casos registrados é relevante para o planejamento e melhora do atendimento na área da saúde, bem como para o desenvolvimento de estratégias que objetivem diminuir o número de casos (LIMA CA, et al., 2020).

O estudo teve como objetivo analisar a prevalência e identificar o perfil dos pacientes acometidos por acidentes por animais peçonhentos no território brasileiro.

\section{MÉTODOS}

Trata-se de um estudo observacional, transversal e descritivo através do levantamento de dados epidemiológicos. As informações foram obtidas no Departamento de Informática do Sistema Único de Saúde (DATASUS), nas subseções do Sistema de Informação de Agravos de Notificação (SINAN) e Sistema de Informações sobre Mortalidade (SIM), durante o mês de setembro e outubro de 2021.

O presente trabalho utilizou dados disponíveis para acesso público na Plataforma DATASUS do Ministério da Saúde, por isso, não necessitou da aprovação de Comitê de Ética em Pesquisa (CEP), conforme resolução no 510 do CNS, de 7 de abril de 2016, artigo 1 e inciso III, que isenta pesquisa que utilize informações de domínio público em Ciências Humanas e Sociais de registro no CEP.

A coleta de dados no SINAN foi direcionada de acordo com os critérios de inclusão para os registros e notificações de acidentes por animais peçonhentos, no período de 2007 a abril de 2021, segundo as variáveis selecionadas "ocorrência por Unidade Federativa", "faixa etária", "sexo", "cor/raça", "escolaridade", "tipo de acidente", "tipo serpente", "tipo aranha" e "evolução caso. Já no SIM, o período analisado foi de 2007 a 2019 , relacionando as variáveis "óbito por região de residência", "sexo", "faixa etária", "cor/raça" e "escolaridade", com objeto de estudo os óbitos confirmados pelo grupo de Classificação Internacional de Doenças (CID-10) X20-W59, X21 e X22.

Foi realizada uma revisão narrativa da literatura com base em 22 artigos selecionados pelos critérios de inclusão relacionados com a temática e variáveis do estudo em questão. Os descritores utilizados foram "Epidemiologia", "Brasil", "Animais peçonhentos". As bases de dados utilizadas foram PubMed, Scielo, Lilacs e Biblioteca Virtual de Saúde (BVS), nos idiomas português, inglês e espanhol, pesquisados durante o mês de setembro e outubro de 2021 . Os critérios de exclusão foram artigos que não contemplavam os descritores utilizados e a temática da pesquisa.

\section{RESULTADOS}

\section{Sistema de Informação de Agravos de Notificação (SINAN)}

Ao analisar os registros do Sistema de Informação de Agravos de Notificação (SINAN) na plataforma do Departamento de Informática do Sistema Único de Saúde (DATASUS) do Ministério da Saúde, colheram-se dados epidemiológicos a respeito de acidentes por animais peçonhentos. Dentre as variáveis existentes, foram selecionadas "ocorrência por Unidade Federativa", "faixa etária", "sexo", "cor/raça", "escolaridade", "tipo de acidente", "tipo serpente", "tipo aranha" e "evolução caso" em concordância com o período entre janeiro de 2007 a abril de 2021. Foram notificados 2.456.217 casos de acidentes com animais peçonhentos no Brasil no período supracitado.

De acordo com as notificações registradas envolvendo acidentes com animais peçonhentos, pode-se identificar que a região Sudeste somou o maior número de registros, com $35,9 \%$, enquanto a Centro-Oeste apresentou a menor, com $4,27 \%$. Ademais, foi possível notar que o Sudeste obteve a maior prevalência em relação ao sexo masculino, com 515.184 casos (20,9\%). Ao mesmo tempo, a região Nordeste ficou responsável pelos maiores casos de acidentes do sexo feminino, atingindo 402.243 casos $(16,4 \%)$. Em relação às unidades federativas (UF) brasileiras, o estado que mais registrou casos no período foi Minais Gerais, com 445.374 casos (18,1\%), em contrapartida com o Amapá, sendo a UF com menos acidentes, com $7.999(0,3 \%)$ (Gráfico 1). 
Gráfico 1 - UF e ocorrência dos casos notificados de acidente por animais peçonhentos, n=2.456.217. Brasil, janeiro/2007-abril/2021.

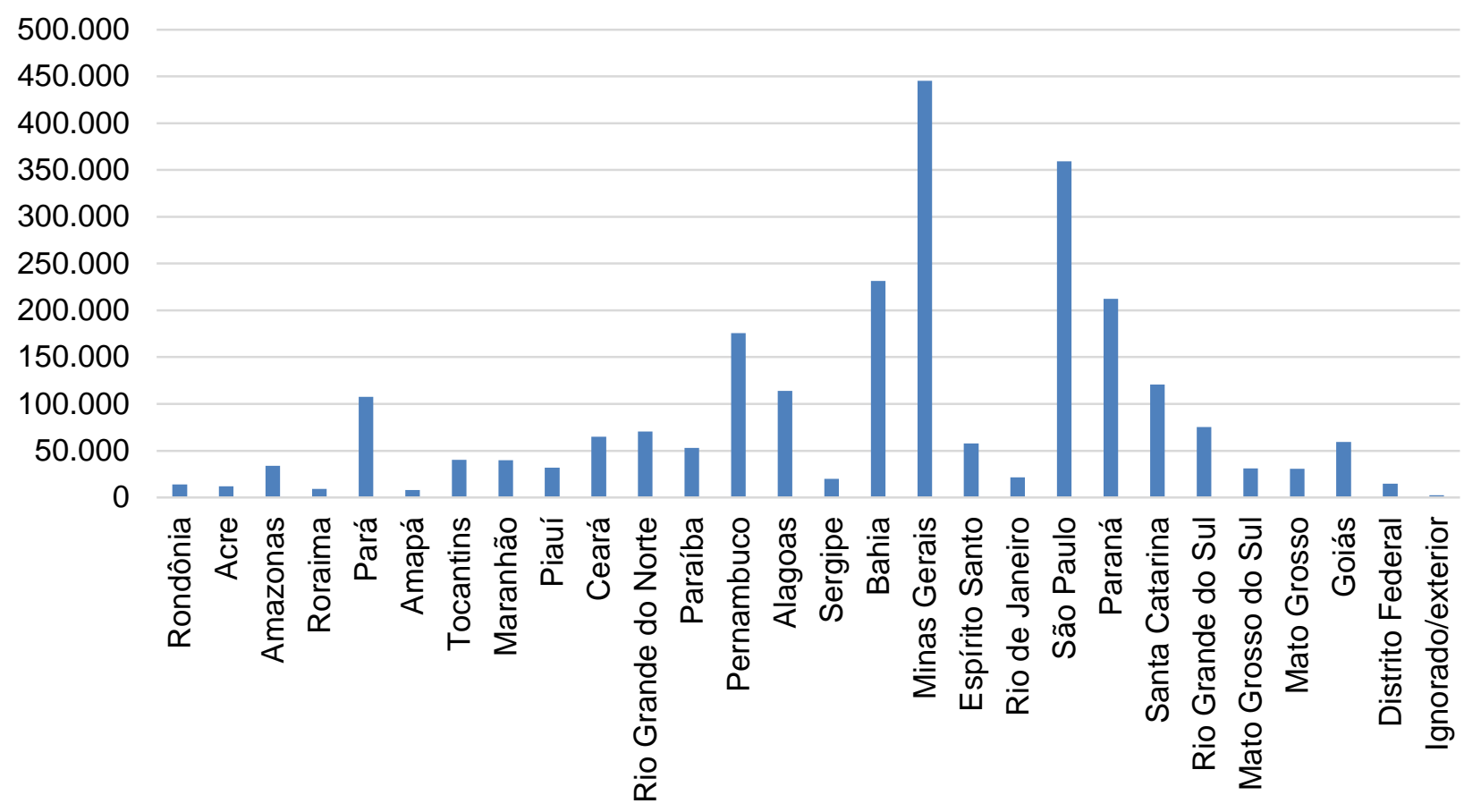

Fonte: Biz MEZ, et al., 2021; dados extraídos do Sistema de Informação de Agravos de Notificação (SINAN) da plataforma DATASUS do Ministério da Saúde.

\section{Faixa etária}

Ao analisar a idade dos pacientes, encontraram-se dois impasses: o primeiro que o número total de casos notificados do período (2.456.217) está em discordância com os registros de faixa etária na plataforma (2.456.209) e o segundo que, ao somar todas as faixas etárias dos registros, totaliza-se 2.474.209, diferindo mais uma vez dos números anteriores. Portanto, baseando-se na soma ( $n=2.474 .209$ ), a população de 20 39 anos foi a mais prevalente (36,6\%), seguida pelo grupo entre $0-19$ anos (26,9\%), então por $40-59$ anos $(26,3 \%), 60-79$ anos $(11,8 \%)$ e, por fim, 80 anos ou mais $(1,3 \%)$. Ainda, um número mínimo de casos foi ignorado $(<1 \%)$.

\section{Sexo}

De acordo com as notificações da Plataforma, nota-se que as prevalências entre homens e mulheres são muito próximas, apresentando-se como $56 \%$ e 43,8\%, respectivamente. Em um número mínimo de agravos $(0,02 \%)$ não houve especificação do sexo do paciente acometido (Gráfico 4).

\section{Raça}

No que diz respeito à raça, os dados analisados demonstraram um número expressivo de casos na população parda, representando 1.051 .491 (42,8\%) do total de acidentes por animais peçonhentos. A raça branca abrange o segundo lugar entre os grupos com 887.134 notificações (36\%), seguido pelos grupos preto $(5,5 \%)$ e indígena (<1\%), sendo o menor índice o da população amarela (<1\%). Entretanto, 13,8\% dos casos foram registrados sem indicação da raça do paciente, classificados como "ignorado" (Gráfico 4).

\section{Escolaridade}

A despeito da escolaridade, é possível relacionar esta variável ao número de ocorrências com animais peçonhentos. Verifica-se que há uma maior prevalência de acidentes no grupo de pessoas com nível de escolaridade do $5^{\circ}$ ao $8^{\circ}$ anos incompletos $(11,4 \%)$ e uma menor no de educação superior incompleta $(1,1 \%)$. Porém, é importante salientar que existe um número expressivo de casos não especificados, sendo classificados como "ignorados" (36,6\%), o que fragiliza a relação (Gráfico 2). 
Gráfico 2 - Relação entre escolaridade e total de casos envolvendo animais peçonhentos, $\mathrm{n}=2.456 .217$. Brasil, janeiro/2007-abril/2021.

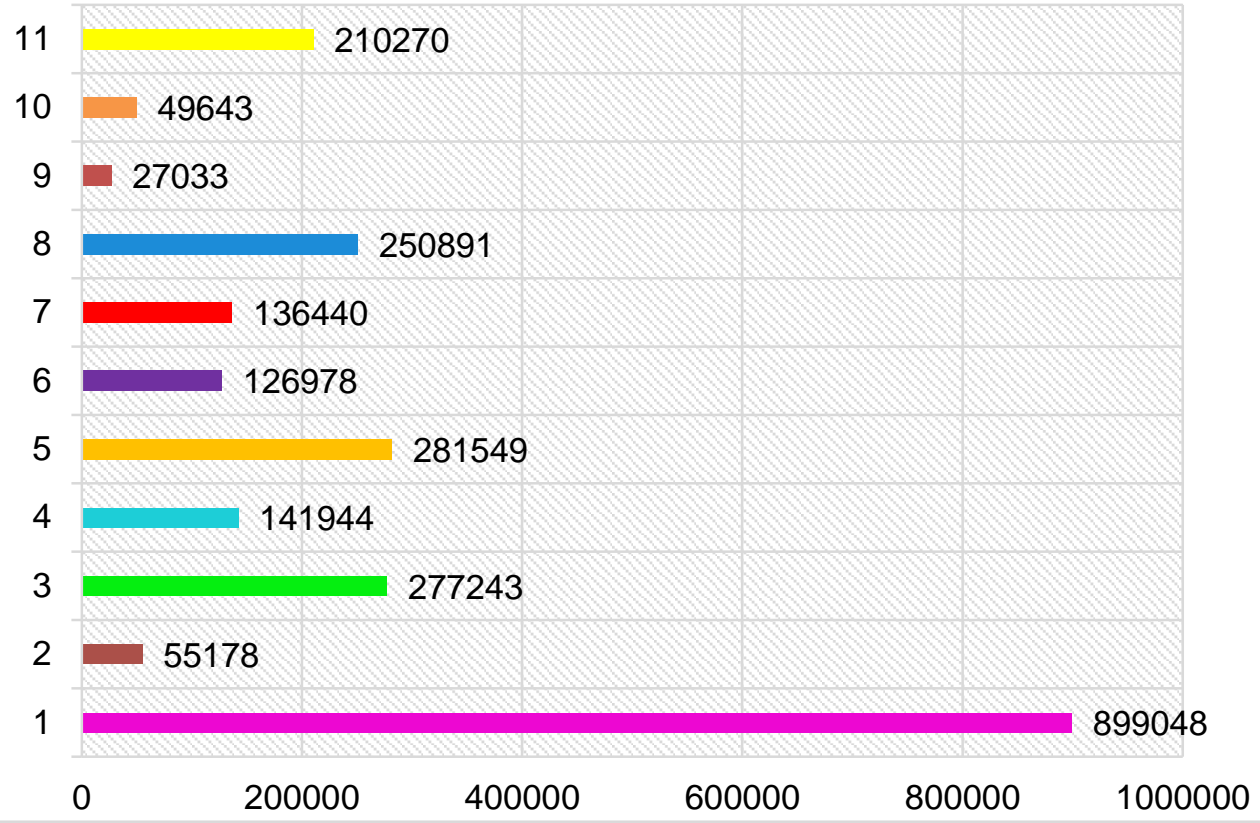

Legenda: EF: Ensino Fundamental. Fonte: Biz MEZ, et al., 2021; dados extraídos do Sistema de Informação de Agravos de Notificação (SINAN) da plataforma DATASUS do Ministério da Saúde.

\section{Tipo de acidente}

Ao avaliar os casos, mais da metade das notificações foram relacionadas a acidentes envolvendo escorpiões, com valores de 1.257 .268 (51,2\%), seguido por serpentes (16,5\%) e aranhas (16,4\%) (Gráfico 3).

Gráfico 3 - Espécies envolvidas nos acidentes por animais peçonhentos, $n=2.456 .217$. Brasil, janeiro/2007-abril/2021.

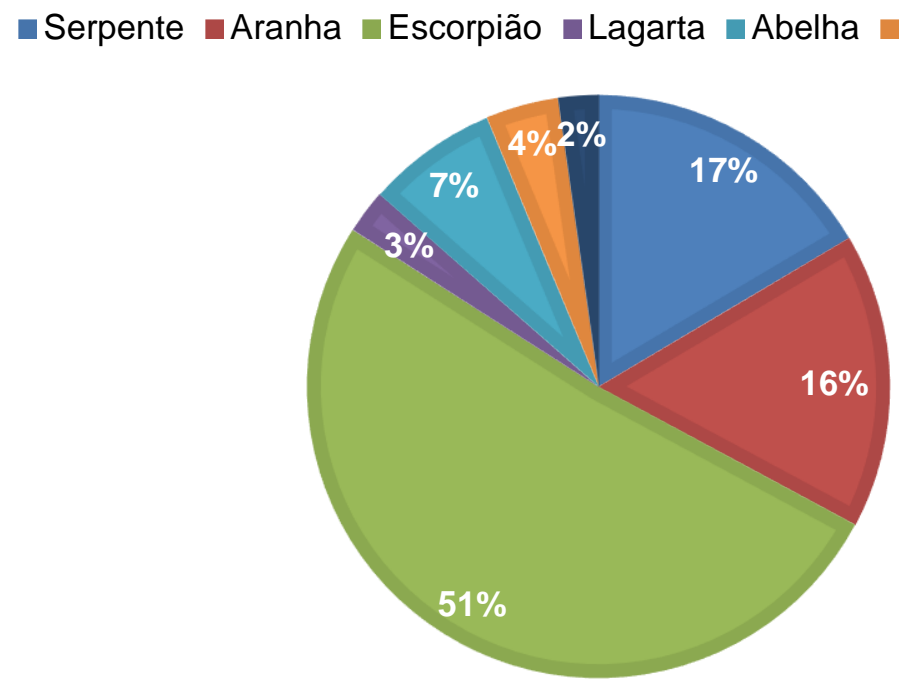

Fonte: Biz MEZ, et al., 2021; dados extraídos do Sistema de Informação de Agravos de Notificação (SINAN) da plataforma DATASUS do Ministério da Saúde.

Vale ressaltar que não há diferenciação entre os gêneros de escorpião no SINAN. Todavia, as serpentes e aranhas são agrupadas em gêneros. Nos acidentes com víboras, o gênero Bothrops foi o mais prevalente, com 73,8\% dos agravos, seguido pelo gênero Crotalus com 7,8\%. Os acidentes provocados pelas aranhas 
apresentaram como principal causador o gênero Loxosceles (com 4,6\%), seguido pelo gênero Phoneutria com 2,3\% e o gênero Latrodectus com menos de 1\%. As demais notificações foram ocasionadas por outros gêneros não listados na Plataforma.

\section{Evolução dos casos após acidente}

Ao analisar a evolução dos casos, verificou-se que houve predomínio da cura sem sequelas $(91,5 \%)$. Além disso, 850 pacientes evoluíram para falecimento em decorrência de agravos causados pelo acidente. Foram ignorados $203.456(8,3 \%)$ eventos, dificultando assim, a identificação do prognóstico e seguimento desses enfermos (Gráfico 4).

Gráfico 4 - Relação entre desfecho, raça e sexo dos casos notificados de acidente por animais peçonhentos, $\mathrm{n}=2.456 .217$. Brasil, janeiro/2007-abril/2021.

Óbito por outra causa

$$
\text { Ignorado }
$$

Óbito pelo agravo notificado

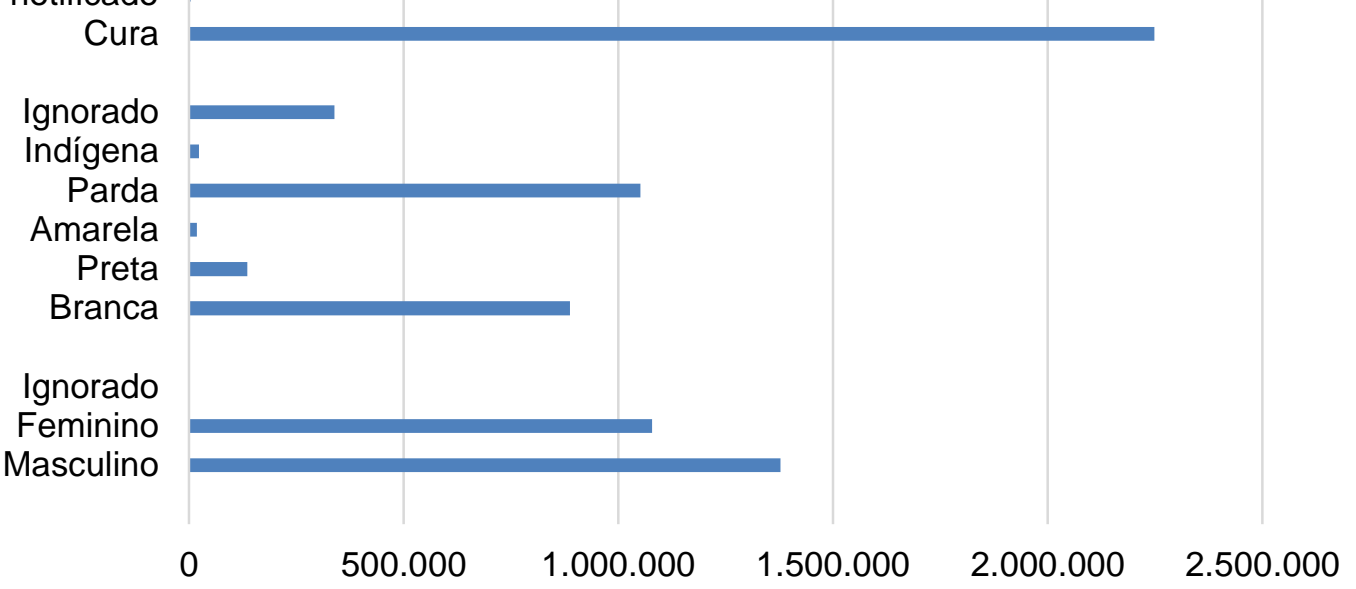

Fonte: Biz MEZ, et al., 2021; dados extraídos do Sistema de Informação de Agravos de Notificação (SINAN) da plataforma DATASUS do Ministério da Saúde.

\section{Perfil epidemiológico do paciente mais afetado}

Levando-se em consideração todos os fatores analisados, foi possível traçar um perfil epidemiológico do paciente mais afetado. Assim, notou-se que o sexo mais acometido foi o masculino (56\%), a faixa etária mais comum é entre 20 e 39 anos, a raça predominante foi a parda $(42,8 \%)$ e o agente agressor de destaque foi 0 escorpião (51,2\%). Quanto à escolaridade, observou-se uma predominância do $5^{\circ}$ ao $8^{\circ}$ ano incompletos $(11,4 \%)$ e a maioria dos pacientes evoluíram para cura sem sequelas (91,5\%) (Figura 1).

Figura 1 - Perfil epidemiológico do paciente mais afetado.

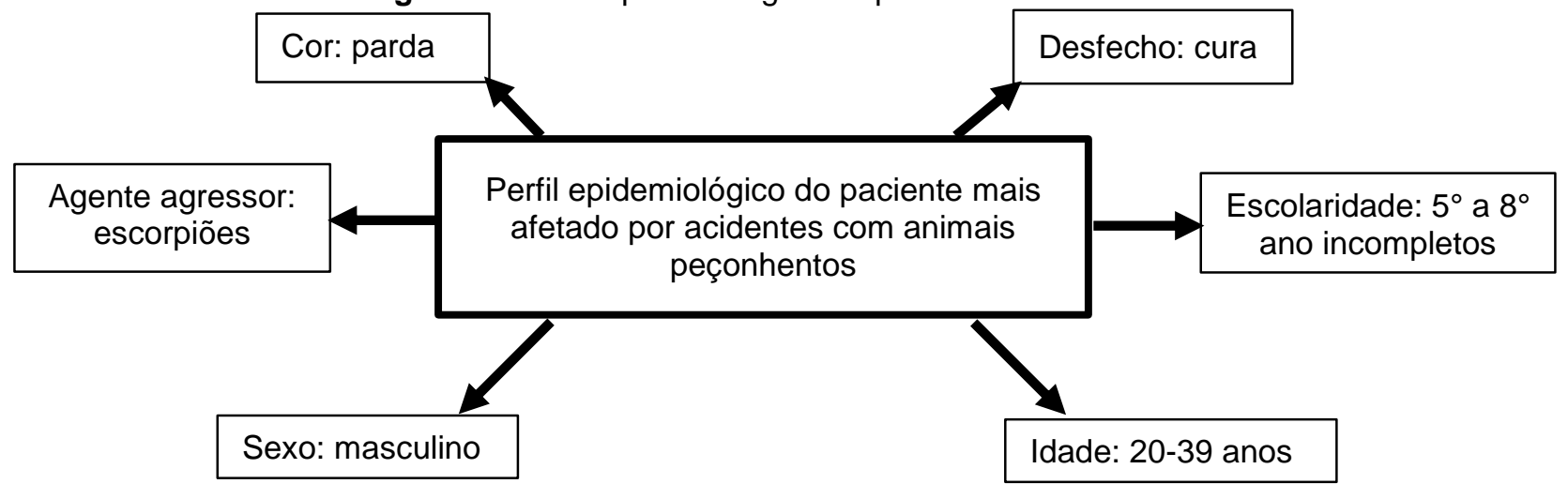

Fonte: Biz MEZ, et al., 2021; dados extraídos do Sistema de Informação de Agravos de Notificação (SINAN) da plataforma DATASUS do Ministério da Saúde. 


\section{Sistema de informação sobre mortalidade (SIM)}

Analisou-se o Sistema de Informações sobre Mortalidade (SIM), também na Plataforma DATASUS do Ministério da Saúde, relacionando-se "óbito por região de residência", "sexo", "faixa etária", "cor/raça" e "escolaridade", no período de 2007 a 2019, com 2.725 falecimentos pelo agravo.

\section{Óbitos}

A região Nordeste se destacou quanto à quantidade de falecimentos, chegando a 415 registros (14,3\%), enquanto a região sul obteve o menor total de óbitos, com 71 (2,60\%). Dentre os anos analisados, o de 2019 obteve a maior soma de mortes com 127 registros (4,6\%), e 2012 o menor número com 86 (3,15\%).

Verificou-se que o maior número de óbitos acometeu a população masculina, com 921 óbitos (33,79\%), ao passo que o sexo feminino registrou $330(12,2 \%)$. A faixa etária com maior apuramento de falecimentos foi a acima dos 60 anos com $238(8,7 \%)$ óbitos, e com o menor, foi em crianças abaixo de 1 ano de idade com apenas 3 mortes $(0,11 \%)$.

Ao avaliar a variável cor/raça, observou-se mais mortes acometendo pessoas pardas $(25,8 \%)$ contrapondo-se à etnia amarela, com apenas $3(0,11 \%)$ óbitos. Em relação à escolaridade, notou-se que a população mais acometida foi a de pessoas com 1 a 3 anos estudados, correspondendo à 334 (12,3\%) óbitos e o público com mais de 12 anos estudados foi o menos acometido com 24 (0,89\%) mortes (Gráfico 5).

Gráfico 5 - Óbitos por acidentes envolvendo animais peçonhentos n=2.725. Brasil, 2007-2019.

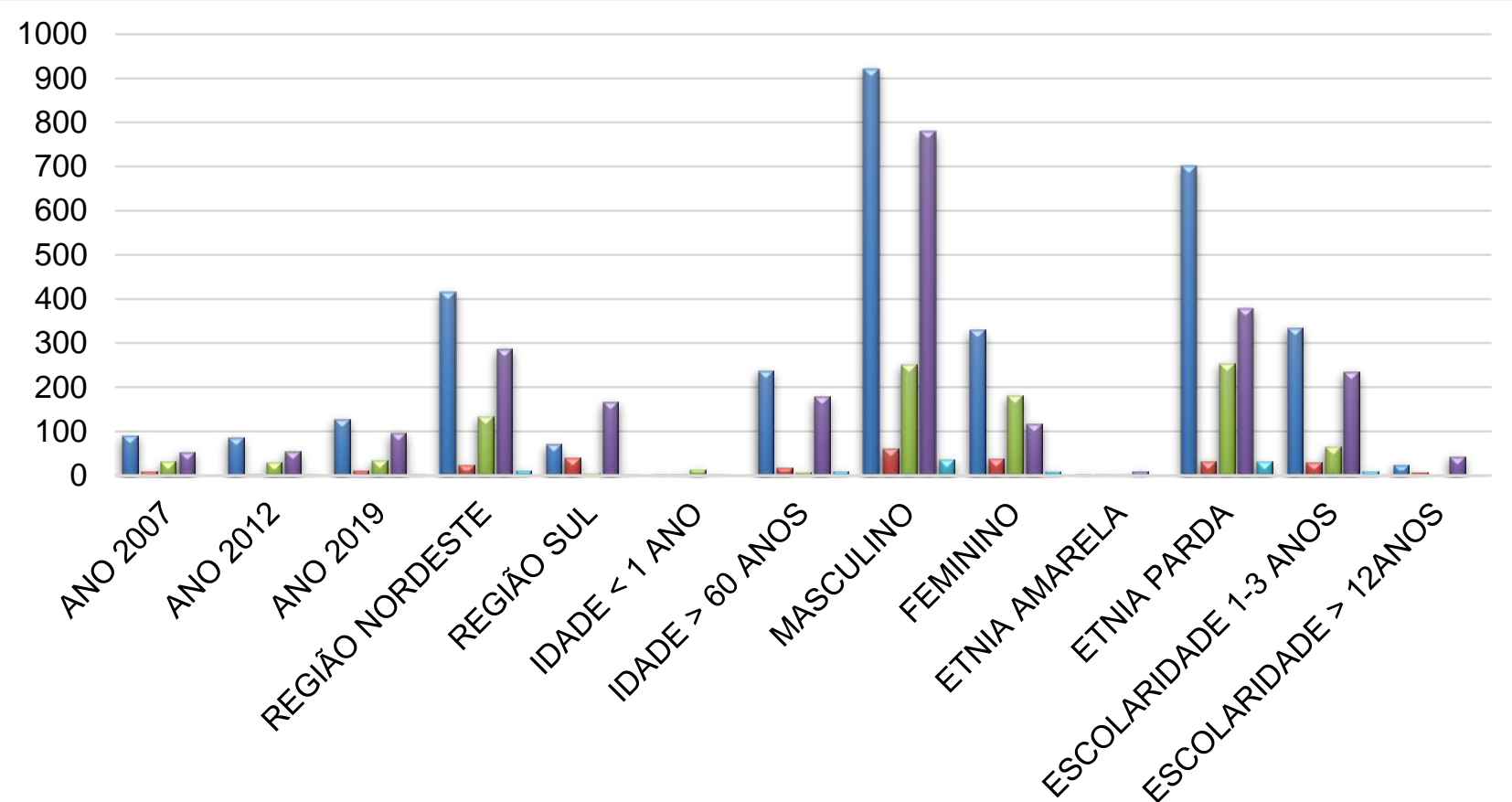

$\square$ Contato c/serpentes e lagartos venenosos

$\square$ Contato c/escorpioes

$\square$ Contato c/outr animais venenosos espec $\square$ Contato c/aranhas venenosas

$\square$ Contato c/abelhas vespas e vespoes

Fonte: Biz MEZ, et al., 2021; dados extraídos do Sistema de Informações sobre Mortalidade (SIM) da plataforma DATASUS do Ministério da Saúde.

\section{DISCUSSÃO}

Segundo os resultados encontrados na plataforma DATASUS, os acidentes com animais peçonhentos corresponderam a 2.456.217 notificações entre 2007 e 2021. Dentre todos os agentes peçonhentos, os que mais causam incidentes são os escorpiões, serpentes e aranhas, correspondendo a $84,1 \%$ do total. Em 
relação às regiões, as que possuem mais notificações registradas são Sudeste, Sul e Nordeste. Esses acidentes se dão muitas vezes pelo crescimento urbano e o contato do homem com ambientes em que esses animais estão inseridos (BRAGA JRM, et al., 2020).

As regiões Nordeste e Sudeste possuem o maior número de casos de morte por agravamento, podendo ser explicado pelo bioma presente em tais regiões. O Sudeste é predominantemente composto pela Mata Atlântica e partes do cerrado, e, em decorrência de seu desmatamento, as víboras passam a migrar para 0 perímetro urbano. Em contrapartida, a região nordeste apresenta os biomas da caatinga e do cerrado, os maiores em extensão no Brasil, justificando a presença de um habitat ideal para as serpentes (MATOS RR e IGNOTTI E, 2020).

Em relação ao perfil epidemiológico do paciente mais acometido pelos acidentes com animais peçonhentos, os resultados identificam uma maior prevalência do sexo masculino, seja envolvendo aranha, escorpião ou serpentes. Esta prevalência pode estar relacionada com a ocupação laboral rural. É importante destacar que os locais mais comuns de acidentes são os membros inferiores, podendo ter relação direta com o tipo de função prestada pelo paciente (BRASIL, 2019). Ao mesmo tempo, em ocorrências com a aranha marrom (Loxosceles), há predomínio do sexo feminino. Dessa forma, uma possível explicação para esta associação é o predomínio de homens nas áreas rurais e de mulheres nas áreas urbanas e domiciliares, que também são os locais de maior presença das aranhas (BOCHNER R e STRUCHINER CJ, 2003).

Ainda dentro do perfil epidemiológico, verifica-se que a raça parda prevalece em números totais nos acidentes com animais peçonhentos, de todas as espécies. Essa predominância também encontra-se em estudos que abrangem regiões específicas do país, como Bahia (RIBEIRO P, et al., 2020) e Tocantins (RODRIGUES AEP, et al., 2019).

Em relação à faixa etária, nota-se uma disparidade no total de casos registrados com o total de casos por idade, evidenciando uma diferença de 8 ocorrências ao total. Como resultado, pode-se indicar uma lacuna na coleta de dados, ou mesmo, possível desacerto no momento da inclusão das informações na plataforma. Ademais, a faixa etária com mais notificações corresponde a indivíduos com idade entre 20 a 39 anos (36,6\%), sendo este o grupo da população economicamente ativo, evidenciando que essa é uma questão de saúde relacionada ao trabalho (FERREIRA ICS e BORGES GH, 2020; SILVA AM, et al, 2015).

Quanto ao agente agressor, os escorpiões são os mais recorrentes $(51,2 \%)$. Estes dados estão em harmonia com trabalho realizado em Minas Gerais e em discordância com os resultados referentes ao Mato Grosso, visto que lá, os acidentes por serpentes ocupam a maior porcentagem (FERREIRA ICS e BORGES $\mathrm{GH}, 2020$ ). Esse número elevado pode estar relacionado a adaptação dos escorpiões ao ambiente urbano, devido a fatores como acúmulo de lixo, temperaturas elevadas e deficiência de saneamento (BRAGA JRM, et al., 2020; LISBOA NS, et al., 2020).

Os acidentes envolvendo escorpiões possuem grandes índices de mortalidade na faixa etária infantil, principalmente nos menores de nove anos, e também nos idosos, podendo ser explicado por fatores decorrentes do veneno e do perfil do paciente (CARMO EA, et al., 2019). O tempo da picada até o primeiro atendimento, o volume de massa corporal, deterioração do mecanismo fisiológico, no caso dos pacientes senis, e a percepção do paciente ao veneno guiam o desfecho, podendo ser satisfatório ou insatisfatório após os eventos (ORTIZ MM, et al., 2021).

De acordo com os dados obtidos, os acidentes com serpentes correspondem a $17 \%$ dos acidentes registrados na plataforma DATASUS. No que diz respeito aos acidentes ofídicos, estes fazem parte da relação de doenças tropicais negligenciadas da OMS. No entanto, ainda são falhas as medidas para a melhora do paciente, visto a gravidade do acidente, a demora da procura por atendimento médico por parte de alguns pacientes, bem como, faltam medidas públicas para um melhor tratamento e prevenção de acidentes. Ainda no que concerne aos acidentes ofídicos, no ano 2000 a 2016, foram registrados 1815 óbitos de um total de 443.912 ocorrências, à vista disso, se torna um importante problema de saúde pública (QUEIROZ TDR, et al., 2021).

As picadas derivadas dos acidentes ofídicos levam primeiramente a uma resposta local, e, em alguns casos, há sintomas mais graves decorrentes de uma forte resposta inflamatória sistêmica ao veneno da 
serpente, que pode possuir neurotoxinas, miotoxinas, além de alterações na cascata de coagulação. $O$ resultado dessas agressões pode ser danoso ao paciente, podendo levar a sequelas e ao óbito se não tratados corretamente (QUEIROZ TDR, et al., 2021).

Em decorrência de um não tratamento rápido e adequado pode ocorrer consequências como rabdomiólise, lesão renal e lesão hepática. A rabdomiólise decorrente da miotoxicidade libera substâncias devido à destruição das fibras musculares, consequentemente podendo ocorrer outras complicações, tal como distúrbios eletrolíticos, síndrome compartimental e alterações cardíacas graves. Por causa da influência do veneno e substâncias toxicas originárias da rabdomiólise, órgãos como fígado e rim podem sofre lesões agudas, sendo a terapêutica focada na preservação das funções dos órgãos para evitar evoluções desfavoráveis (QUEIROZ TDR, et al., 2021).

No tocante sobre a evolução dos casos após os acidentes, é possível notar superioridades dos eventos curados, entretanto, nos últimos 14 anos, foram registrados 3850 óbitos relacionados a evoluções desfavoráveis. O maior número de mortes associou-se às serpentes e ao gênero Bothrops, entretanto essa estimativa pode ter sido notificada em excesso devido à similaridade com outros gêneros como Lachesis. Por esse e outros motivos, como a localização geográfica em todo Brasil, aumento do desmatamento e aproximação com o ambiente humano, as serpentes do gênero Crotalus estão mais relacionadas aos desfechos desfavoráveis que resultam em morte (MATOS RR e IGNOTTI E, 2020).

Segundo os dados encontrados na plataforma DATASUS, quanto a evolução dos casos, em $8,3 \%$, não se tem registro de como o quadro do paciente evoluiu, à vista disso, se torna moroso o processo para análise dos fatores que possam buscar um prognóstico favorável do paciente, visando a melhora sem ou com mínimas sequelas, bem como, uma maior disponibilidade dos soros para tratamento. Haja vista, em 2014 os acidentes ofídicos, foram os acidentes com maior taxa de mortalidade (QUEIROZ TDR, et al., 2021).

No que concerne à taxa de mortalidade observada no SIM de 2007 a 2019, verificou-se 2.725 óbitos devido a acidentes com animais peçonhentos. Diante disso, nota-se como algo determinante para o prognóstico do paciente o tempo entre a picada e o atendimento (SILVA JH, et al., 2017). Além disso, a espécie do animal, a idade do paciente, a quantidade de veneno inoculado também são fatores que contribuem para um desfecho trágico (BRASIL, 2019). Outro fator relacionado com os óbitos é a reação alérgica, em que o paciente evolui para um choque anafilático como observado em alguns acidentes por picadas de abelhas (MESCHIAL WC, et al., 2013).

\section{CONCLUSÃO}

Este estudo mostra que há uma alta prevalência de acidentes por animais peçonhentos no Brasil e a correlação com o processo de urbanização, ocupação laboral e bioma local com o número de casos. O perfil epidemiológico dos acometidos são jovens (20-39 anos) do sexo masculino, baixa escolaridade e de cor parda. Em contrapartida, a mortalidade deste evento associa-se a extremos de idade, espécies dos animais e eficácia do atendimento. Dados discrepantes foram encontrados no estudo, mostrando a importância da ampliação e melhoria das notificações compulsórias para que se verifique melhor planejamento público de prevenção e terapêutica.

\section{REFERÊNCIAS}

1. BOCHNER R, STRUCHINER CJ. Epidemiologia dos acidentes ofídicos nos últimos 100 anos no Brasil: uma revisão. Revista Cadernos de Saúde Pública, 2003: 19(1): 07-16.

2. BRAGA JRM, et al. Epidemiology of accidents involving venomous animals in the State of Ceará, Brazil (2007-2019). Revista da Sociedade Brasileira de Medicina Tropical, 2021: 54.

3. BRASIL. Acidentes de trabalho por animais peçonhentos entre trabalhadores do campo, floresta e águas, Brasil 2007 a 2017. Observatório do cuidado: Vigilância em Saúde, 2019. Disponível em: https://repositorio.observatoriodocuidado.org/bitstream/handle/handle/1993/BoletimEpidemiologico_v.50_Mar_2019. pdf?sequence=1\&isAllowed=y. Acesso em: 29 set. 2021. 
4. CARMO EA, et al. Fatores associados à gravidade do envenenamento por escorpiões. Revista Texto \& ContextoEnfermagem, 2019; 28: e20170561.

5. CHEUNG R, MACHADO C. Acidentes por animais peçonhentos na região dos Lagos, Rio de Janeiro, Brasil. Journal Health NPEPS, 2017; 2(1): 73-87.

6. FEOLA A, et al. Autopsy Findings in Case of Fatal Scorpion Sting: A Systematic Review of the Literature. Healthcare, 2020; 8: 325-335.

7. FERREIRA ICS, BORGES GH. Perfil epidemiológico dos acidentes causados por animais peçonhentos no município de Patrocínio, Minas Gerais: retrato de uma década. Revista de Epidemiologia e Controle de Infecção, 2020; 10(4): 1-10.

8. LADEIRA CGP, MACHADO C. Epidemiologia dos acidentes com animais peçonhentos na região de Ponta Nova, Minas Gerais, Brasil. Jornal Health NPEP, 2017; 2(1): 40-57.

9. LIMA CA, et al. Vigilância em Saúde: Acidentes e óbitos provocados por animais peçonhentos na região sudeste Brasil 2005-2015. Revista de Pesquisa (Universidade Federal do Estado do Rio de Janeiro. Online), 2020; 12 : 20-28

10. LISBOA NS, et al. Escorpionismo no Extremo Sul da Bahia, 2010-2017: perfil dos casos e fatores associados à gravidade. Epidemiol.serv.saúde, 2020; 29(2): 1-12.

11. MATOS RR, IGNOTTI E. Incidência de acidentes ofídicos por gêneros de serpentes nos biomas brasileiros. Ciência \& Saúde Coletiva, 2020; 25(7).

12. MESCHIAL WC, et al. Internações hospitalares de vítimas de acidentes por animais peçonhentos. Rev Rene. 2013; 14(2): 311-319.

13. ORTIZ MM, et al. Acidentes por escorpião Tityus sp. (scorpiones: Buthidae) em crianças: discussão de dois óbitos. Research, Society and Development, 2021; 10(2).

14. QUEIROZ TDR, et al. Rabdomiólise maciça e hepatite aguda secundários ao envenenamento crotálico: um relato de caso. Revista Eletrônica Acervo Saúde, 2021; 13(10).

15. RIBEIRO PHB, et al. Acidentes por animais peçonhentos: panorama epidemiológico na Bahia, entre 2015 e 2019. Revista de atenção primária a saúde, 2021; 23.

16. RODRIGUES AEP, et al. Perfil epidemiológico dos acidentes por animais peçonhentos no Tocantins no ano de 2019. Revista de Patologia do Tocantins, 2020; 7(4): 47-53.

17. SANCHEZ-CASTRO EE, et al. Mesenchymal Stromal Cell-Based Therapies as Promising Treatments for Muscle Regeneration After Snakebite Envenoming. Immunol, 2021; 11: 1-17

18. SILVA AM, et al. Acidentes com animais peçonhentos no Brasil por sexo e idade. Journal of Human Growth and Development, 2015; 25(1): 54-62.

19. SILVA JH, et al. Perfil epidemiológico dos acidentes com animais peçonhentos em Tangará da Serra-MT, Brasil (2007-2016). Journal Health NPEPS, 2017; 2(1): 5-15.

20. TAVARES AV, et al. Epidemiologia da lesão por animais peçonhentos no estado do Rio Grande do Norte, Nordeste do Brasil. Ciência \& Saúde Coletiva, 2020; 25(5): 1967-1978.

21. WARRELL DA. Venenous Bites, Stings, and Poisoning. Infectious Disease Clinics of North America, 2019; 33(1): 1738. 